\title{
A Study on the Issues of Conducting China's Manufacturing Power Strategy
}

\author{
Kong Dejing ${ }^{1}$, Yan Jianlin ${ }^{2}$, Yang Xiaoying ${ }^{2}$, Qu Xianming ${ }^{2}$ \\ 1. School of Modern Post, Beijing University of Posts and Telecommunications, Beijing 100876, China \\ 2. The CAE Centre for Strategic Studies, Beijing 100088, China
}

\begin{abstract}
In 2015, the Chinese Academy of Engineering launched a major advisory project: Manufacturing Power Strategy II. This project conducted a systematic and in-depth analysis of the major obstacles affecting China's position as a manufacturing power, presented relevant suggestions, and produced a research report. This study is based on a preliminary assessment of the project. It considers related issues such as manufacturing power indexes, the Made in China 2025 strategy, typical cases, and experts' opinions by means of data mining, case studies, and expert interviews. The results indicate the main factors that obstruct the development of China as a manufacturing power. These factors are the growth pattern of manufacturing in China, the unbalanced implementation of the five projects of the Made in China 2025 strategy, the similar focus of different local governments on industrial development, and the risk of neglecting traditional manufacturing. In order to solve these issues, this study suggests promoting high-quality manufacturing and technological transformation in order to accelerate the remodeling of China's economic growth pattern and the upgrading of traditional manufacturing. The study also suggests coordinating the implementation of the five projects with local industrial policies in order to develop China's manufacturing power strategy more efficiently.
\end{abstract}

Keywords: manufacturing power; Made in China 2025; manufacturing power index; strategic countermeasures

\section{Introduction}

Manufacturing is the most important industry of China's national economy. It is the main engine of economic growth and plays a key role in improving, transforming, and upgrading economic development. Recently, the need to attract the advanced techniques used by developed economies and the other techniques used by developing economies has influenced manufacturing in China and significantly challenged the country's manufacturing power. Moreover, the technological and industrial revolution has given an opportunity to accelerate the transformation and upgrading of manufacturing and improve the development of innovation in China.

From 2013 to 2014, the Chinese Academy of Engineering conducted a key advisory project called First-phase Research on the Manufacturing Power Strategy (Phase I). It also proposed a three-step strategy for turning China into the foremost manufacturing power in the world. Strategic suggestions for implementing the Made in China 2025 initiative were also proposed to central government. Based on the extensive work that took place at the first phase, the research group organized a further key advisory project called Research on the Manufacturing Power Strategy (Phase II) from 2015 to 2016. Besides undertaking systematic and in-depth research into the major issues, the research group cooperated with the State Council's leadership team to create and implement the $1+\mathrm{X}$ Action Plan for Made in China 2025.

Received date: April 25, 2017; Revised date: May 26, 2017

Corresponding author: Qu Xianming, Strategic Study of CAE, Professor of Engineering. Major research fields include advanced manufacturing technology, and industry and technology development strategy. E-mail: qu.xianming@163.com

Funding program: CAE Advisory Project "Research on Manufacturing Power Strategy (Phase II)" (2015-ZD-15).

Chinese version: Strategic Study of CAE 2017, 19 (3): 006-012

Cited item: Kong Dejiang et al. A Study on the Issues of Conducting China's Manufacturing Power Strategy. Strategic Study of CAE, https://doi.org/10.15302/ J-SSCAE-2017.03.002 


\section{The implementation status of the Made in China 2025 report}

As noted in the Made in China 2025 report, the action plan's basic guidelines are to be innovation-driven, emphasize quality over quantity, achieve green development and optimize the structure as well as the basic principles of market-orientation, be government-led, focus on the present, aim at the long-term future, make overall progress, make the key breakthroughs, pursue independent development, and realize open cooperation. A threestep strategy should also be implemented to achieve the strategic goal of building a manufacturing power [1].

The Made in China 2025 initiative can be seen as a banner for uniting social forces and gathering all of society's resources effectively. In this way, the environment for undertaking a national effort to build manufacturing power has been created. The Made in China 2025 scheme will be the most important blueprint for China's future manufacturing industry. It has not only confirmed the fundamental status of the manufacturing industry in the national economy; it has also strengthened the resolve to turn China into a manufacturing power. Now that it has been available for some while, the Made in China 2025 report has attracted much attention from all levels of government and become a popular topic for discussion among the Chinese people. The Baidu search index for keywords such as "Made in China 2025"and "craftsman's spirit" shows a remarkable increase in interest in these words since 2015. Provinces, autonomous regions, municipalities, and special administrative regions in China (except Tibet) have proposed action plans to develop the manufacturing industry, strengthen China's overall efforts for such development, and create a favorable social atmosphere for promoting further development.

According to The Current Status of Advancing the Implementation of Made in China 2025, a report released by the Ministry of Industry and Information Technology on March 11, 2017, significant progress has been made in five fields since the Made in China 2025 strategy was implemented in 2015. These fields are a national manufacturing innovation center, intelligent manufacturing, strengthened industrial development at the grassroots level, green manufacturing, and high-end equipment innovation. Further, by the end of 2016, a Power Battery Innovation Center was officially registered and founded. In addition, a proposal for a National Additive Manufacturing Innovation Center has been discussed and approved, and 19 province-level manufacturing innovation centers have been established. Since 2015, 226 innovative projects involving intelligent manufacturing and digital factory standardization have also been conducted. Of these, 109 pilot demonstration projects for intelligent manufacturing have been selected. According to the preliminary survey, the production efficiency of the first batch of demonstration enterprises has improved by 38 percent on average. Moreover, on average, the energy utilization rate has improved by 9.5 percent, operational costs have decreased by 21 percent, and the product research and development cycle has been shortened by 35 percent. With regard to strengthened industrial development at the grassroots level, some bottleneck problems related to basic core components, key basic materials, and advanced basic technologies have been solved. In terms of green manufacturing, 57 reward and demonstration projects that aim to reduce high-risk pollutants have been implemented. The energy consumption for each unit of industrial added value has also decreased by approximately 5 percent. As regards to high-end equipment innovation, there are various achievements that include a high-precision numerical control (NC) gear grinder, a multi-axis precision heavy-duty machine tool, an NC stamping production line, and an independently developed unmanned submersible known as "Haidou."

\section{Problems facing the task of becoming a manufacturing power}

Since the Made in China 2025 strategy was implemented, significant progress has been made for each key task, step by step. Efforts to build robust manufacturing provinces, cities, and districts have been made in different regions. Numerous manufacturing enterprises have made substantial attempts to promote industrial transformation, upgrade current systems, and build manufacturing power. However, according to the 2015 China Manufacturing Power Development Index Report and the surveys of relevant experts, the strategy still faces with challenges.

This study considers the growth mode of China's manufacturing industry, the implementation of the five major projects of the Made in China 2025 strategy, the key development points of the country's manufacturing industry, and the policy guide. It then analyzes the problems that China's manufacturing industry has faced during the first two years since the introduction of the Made in China 2025 strategy.

\subsection{China's manufacturing industry still relies on the scale expansion model}

As shown by a comprehensive analysis of the manufacturing power index, the increase for China relies mainly on the growth of the scale development index. Sustainable development, quality, and efficiency are still the bottlenecks that are hindering the country's further manufacturing industry development.

Indeed, China is far behind developed countries such as the United States of America (USA), Germany, and Japan in terms of the secondary index for sustainable development. As can be seen in Table 1 [2] regarding this secondary index, each unit of added value for China's manufacturing industry involves just 5.95 license patents on average. In contrast, the USA and Japan 
outperform China with 2.8 and 2.3 times more patents. China's input into research and development (R\&D) for the manufacturing industry is slightly more than that of the UK; however, the average comparable input of the other four countries is approximately 1.7 times that of China. In addition, the proportion of personnel engaged in R\&D in China's manufacturing industry is approximately 10 percent of the average of the other five countries. China is also outperformed by the other five countries in terms of each unit of added value for energy consumption within the respective manufacturing industries. However, compared with the other three secondary indexes, the gap is relatively smaller and is approximately half that of Germany, Japan, and the UK.

Addressing quality and efficiency is an urgent task that faces China's manufacturing power strategy. Priority should be given to improving labor productivity within the manufacturing industry and enhancing the competitive strength of high-tech products. As can be seen in Table 2 [2], which compares the secondary indexes of quality and efficiency in 2014, China's manufacturing industry has the lowest rate of added value. This rate is approximately 60 percent of the average added value of the other five countries. Although the sales profit rate of China's manufacturing is slightly higher than that of Japan and the UK, it is still lower than that of the USA, Germany, and South Korea. The index of labor productivity for China's manufacturing industry is 2.31 , which is approximately 20 percent of that of the USA, Germany, and Japan; 25 percent of that of South Korea; and 33 percent of that of the UK. Further, the index of competition in high-tech product trading for the other five countries ranges from 6.32 to 7.92 . In contrast, the index for China is only 2.09 .

\subsection{The obvious differences in the implementation of the five key projects}

The Made in China 2025 strategy has five important projects; namely, a national manufacturing innovation center, intelligent manufacturing, strengthened industrial development at the grassroots level, green manufacturing, and high-end equipment innovation. The aims are to solve the foremost technical problems that have hindered the growth of key fields for a long time, make breakthroughs in the manufacture of common products and the development of technologies, and improve the overall competitiveness of China's manufacturing industry. Having been implemented for more than a year, the five projects have displayed the following overall tendencies: intelligent manufacturing is gaining popularity, which is not the case for green manufacturing; strengthened industrial development at the grassroots level has not yet received significant support; and the creation of the innovation center has not run smoothly.

Compared with green manufacturing, intelligent manufacturing has attracted greater attention from society in general and has also gained support from most local governments and enterprises. Since 2015, the Baidu search index for the keyword "intelligent manufacturing" has remained above 450. However, the keyword "green manufacturing" does not exist in the index bank. Besides attracting wide attention, intelligent manufacturing has also received significant support from local governments. For example, 36 pilot and demonstration projects for intelligent manufacturing were selected for development in Guangdong in 2016. Guangdong People's Government also released a plan called the Development Plan for Intelligent Manufacturing in Guangdong from 2015 to 2025. By 2020, the industrial added

Table 1. Indexes for sustainable development, 2014.

\begin{tabular}{lcccc}
\hline & $\begin{array}{c}\text { Index for patents for each } \\
\text { unit of added value in the } \\
\text { manufacturing industry }\end{array}$ & $\begin{array}{c}\text { Input into the R\&D of the } \\
\text { manufacturing industry }\end{array}$ & $\begin{array}{c}\text { The proportion of personnel } \\
\text { engaged in R\&D in the } \\
\text { manufacturing industry }\end{array}$ & $\begin{array}{c}\text { Each unit of added value in } \\
\text { the manufacturing industry for } \\
\text { energy consumption }\end{array}$ \\
\hline China & 5.95 & 2.83 & 0.18 & 4.33 \\
USA & 16.67 & 4.21 & 1.75 & 6.32 \\
Germany & 6.90 & 4.20 & 1.88 & 9.40 \\
Japan & 13.67 & 5.51 & 1.96 & 8.74 \\
UK & 1.91 & 2.78 & 0.82 & 9.33 \\
South Korea & 4.54 & 5.65 & 1.05 & 5.58 \\
\hline
\end{tabular}

Table 2. Indexes for quality and efficiency, 2014.

\begin{tabular}{lcccc}
\hline & Rate of added value in the manufacturing industry & Labor productivity & Competition in high-tech product trading & Sales profit rate \\
\hline China & 2.15 & 2.31 & 2.09 & 2.99 \\
USA & 3.77 & 11.18 & 6.32 & 3.21 \\
Germany & 3.88 & 10.21 & 7.92 & 3.18 \\
Japan & 3.61 & 11.02 & 7.57 & 2.42 \\
UK & 3.16 & 7.14 & 6.95 & 2.85 \\
South Korea & 3.33 & 9.22 & 7.03 & 3.12 \\
\hline
\end{tabular}


value of intelligent equipment in the province is due to reach 400 billion RMB. Further, according to the 13th Five-Year Plan of Intelligent Manufacturing Equipment in Hubei Province, the industrial value of intelligent manufacturing equipment in this province is set to reach 200 billion RMB by 2020 . The efforts to build a national-level intelligent manufacturing equipment base will also accelerate. In March 2016, Wuhan Xinxin Semiconductor Manufacturing Corp. implemented a memory base in Gaoxing District of Donghu of Wuhan with a total investment of 24 billion US dollars [3]. In contrast, the strategy for green manufacturing has not yet taken form. As of March 2017, none of the pilot cities that are part of the Made in China 2025 strategy had focused on the development of green manufacturing. Moreover, with regard to the application to central government for special funds, the evaluation of applications for the system integration of green manufacturing only started at the beginning of 2017, thereby lagging far behind intelligent manufacturing. Intelligent manufacturing can make progress because a breakthrough in a certain technology leads to overall improvement in the manufacturing industry. However, green manufacturing still involves a high degree of complexity. As part of the process of promoting green manufacturing comprehensively, policymakers and executors must comprehensively consider the influence of various factors, such as low carbon, green, and recycling initiatives, on the balanced development of the manufacturing industry alongside environmental protection. In sum, green manufacturing is a long-term, systematic task, the achievement of which cannot be easily noted.

Solving the problem of weak industrial capability is complicated and requires a methodical approach. Indeed, the most fundamental aspects, materials, and technologies of manufacturing industry represent the core competitiveness of a country. This situation means that foreign countries can exert control more easily. Some developed countries have tried to prevent Chinese enterprises from entering core fields in the name of national security. For example, President Obama banned the Fujian Grand Chip (FGC) Investment Fund from acquiring the business of the German semiconductor producer, Aixtron, in the USA because he insisted that gallium nitride $(\mathrm{GaN})$ could be used for military purposes. Further, using the strength of their capital and technological advantages regarding core components and key materials, some enterprises from the USA, Germany, and Japan have obstructed Chinese enterprises that supply parts. As a result, such Chinese enterprises have been unable to enter the relevant supply chain system or purchase, through mergers and acquisitions, foreign high-end companies that manufacture parts and materials. For example, after the Nantong Zhenkang Welding Electromachinery Co., Ltd. and the Qinchuan Machine Tool Group Co. Ltd. made a technical breakthrough with a rotary vector (RV) reducer, a Japanese company called Nabtesco lowered its price immediately so as to reduce the product's profit. Consequently, because the two Chinese companies suffered a loss, they could not engage in innovation and industrialization. Moreover, the Japanese company even threatened to terminate its supplies to Chinese and foreign robot enterprises if they used the reducers made by the Chinese enterprises.

Nonetheless, a National Power Battery Innovation Center has been founded in China. A proposal for a National Additive Manufacturing Innovation Center has also been evaluated by experts. Moreover, many local governments have encouraged the founding of manufacturing innovation centers. However, the establishment mechanism of these innovation centers is still similar to that of the Guangdong HUST Industrial Technology Research Institute (hereafter referred to as the Industrial Technology Research Institute), the Industrial Technology Alliance, and Collaborative Innovation Industrial Parks, for example. Thus, it is uncertain whether the innovation centers can achieve their anticipated goals. The main factors that influence the performance of innovation centers include the demands of local industry, talent accumulation, operational mechanisms, and the policy environment [4]. Among these factors, operational mechanisms have the most obvious effect on innovation centers' performance. In recent years, $22 \mathrm{R} \& \mathrm{D}$ institutes have been founded in Dongguan City. Among these, only the Industrial Technology Research Institute has made any outstanding achievements. Most of the research institutes have only undertaken medium-end or low-end projects. Moreover, there is great concern about their future development after governmental support ends. As shown by the successful experience of the Industrial Technology Research Institute, innovation plays a key role. The Industrial Technology Research Institute has adopted an operational style that does without administrative rankings, a staffing system, and fixed operational expenses. Instead, it adheres to the concepts of innovation, creation, and entrepreneurship; it has also made significant efforts to explore innovation within the innovation, industrial, and funding chains. In sum, it has set a good example for a new style of research institute. According to the statistical data of the Industrial Technology Research Institute, it has supported high-tech business incubators including three companies that have become listed on China's new over-the-counter (OTC) market, two companies that have joined the stock exchange, and three companies that have become back-up enterprises to others that are going public in Dongguan. Moreover, the Xi'an Institute of Optics and Precision Mechanics has made significant achievements in terms of the industrialization of technology. As of June 2016, the institute has successfully incubated 100 high-tech companies with a total output value of 3 billion RMB. These companies have paid taxes of 75 million RMB and employed 4500 people [5].

\subsection{The limited attention paid to traditional manufacturing development}

Provinces, autonomous regions, municipalities, and special 
administrative regions in China have rapidly turned their attention to 10 key developmental fields. Such a change of approach means that traditional manufacturing is faced with the risk of being neglected. According to the survey and analysis of the key developmental fields in the action plan of the Made in China 2025 report (Fig. 1), more than 20 regions choose to focus on the development of new materials, new-generation information technology (IT), energy conservation, and biological medicine. In addition, more than 10 regions choose to focus on machine tools and robotics, and aerospace, marine, railroad, agricultural, and electronic equipment. However, few regions consider traditional manufacturing fields such as chemical engineering, construction materials, metallurgy, textile, and food processing. Apart from new-generation IT, the other nine key developmental fields are on a relatively small scale. The neglect of traditional manufacturing's development will have a serious impact on maintaining the scale of the national economy and realizing sustainable and stable growth.

Compared with the high-tech and new fields, traditional manufacturing clearly has weaker innovative power. According to the Statistical Communiqué of National Input into Science and Technology in 2014 released by the National Bureau of Statistics, the national input into R\&D totaled 1.30156 trillion RMB in 2014. Further, the ratio of R\&D expenses to GDP was 2.05 percent, which is 0.04 percent higher than in 2013; the R\&D input in the manufacturing industry reached 889.09 billion RMB; and the ratio of $R \& D$ input to GDP was 0.91 percent. In the manufacturing industry, the proportion of $R \& D$ input for transportation facilities and instruments was higher than 2 percent for both. However, in traditional manufacturing fields, such as agricultural food processing, food production, aquatic products, and textile garments, the proportion of $\mathrm{R} \& \mathrm{D}$ input is less than 0.5 percent.
There are urgent quality-related problems in traditional manufacturing fields that are closely related to public welfare, such as agricultural food processing and textile garments. As shown by the comparison of the quality competition indexes in Fig. 2 for manufacturing fields from 2011 to 2014 (data source: The Communiqué of National Manufacturing Quality Competition Index in 2011, The Communiqué of National Manufacturing Quality Competition Index in 2012, The Communique of National Manufacturing Quality Competition Index in 2013, and The Communiqué of National Manufacturing Quality Competition Index in 2014 released by the General Administration of Quality Supervision, Inspection and Quarantine), the indexes for pharmaceutical production and electronic equipment manufacturing are increasing year after year. In 2014, their quality competition indexes exceeded 91 . The quality competition indexes of furniture manufacturing, garment and dress production, textile production, and agricultural food processing are less than 79 and do not show an upward tendency. The quality competition indexes of food production and papermaking from 2011 to 2014 do not change a great deal and remain below 81 . Moreover, as shown by the import and export commodity structure (data source: China's General Administration of Customs), import and export volumes are increasing from 2014 for items such as dairy and egg products; essential oils, perfume, and cleaning products; clothes and shoes; travel items; and handbags. This finding may indirectly indicate that the quality of some domestic products has not yet gained high recognition from Chinese consumers.

\subsection{The obvious similarities in the key developmental fields of different regions}

Many local governments have made plans to invest in the 10 key developmental fields proposed by the Made in China

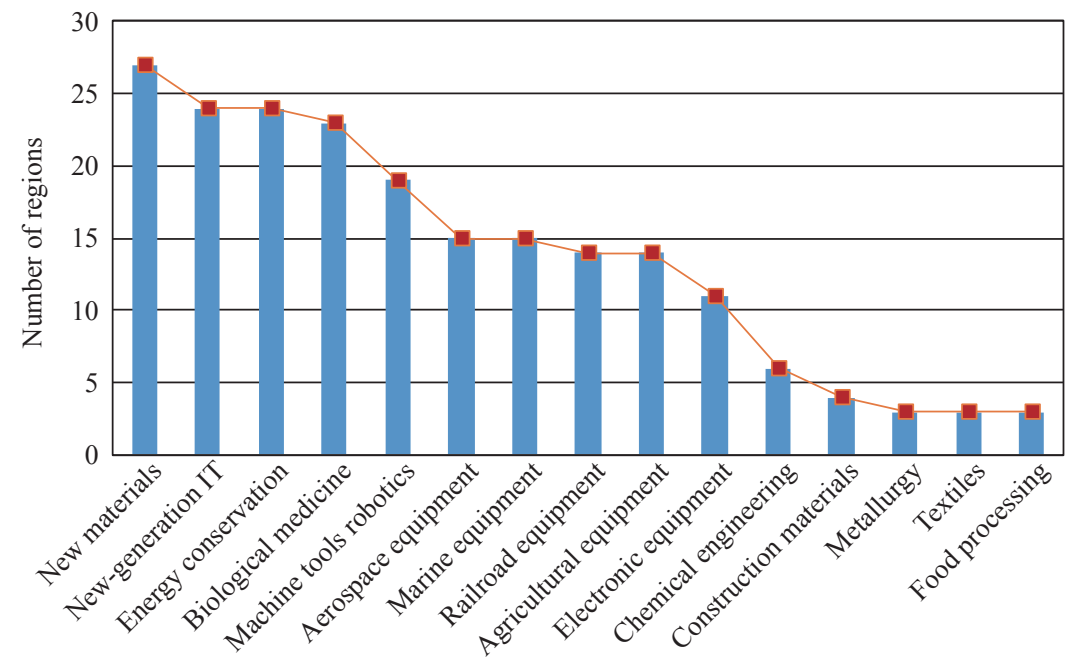

Key development fields

Fig. 1. The key developmental fields of the provinces and regions. 


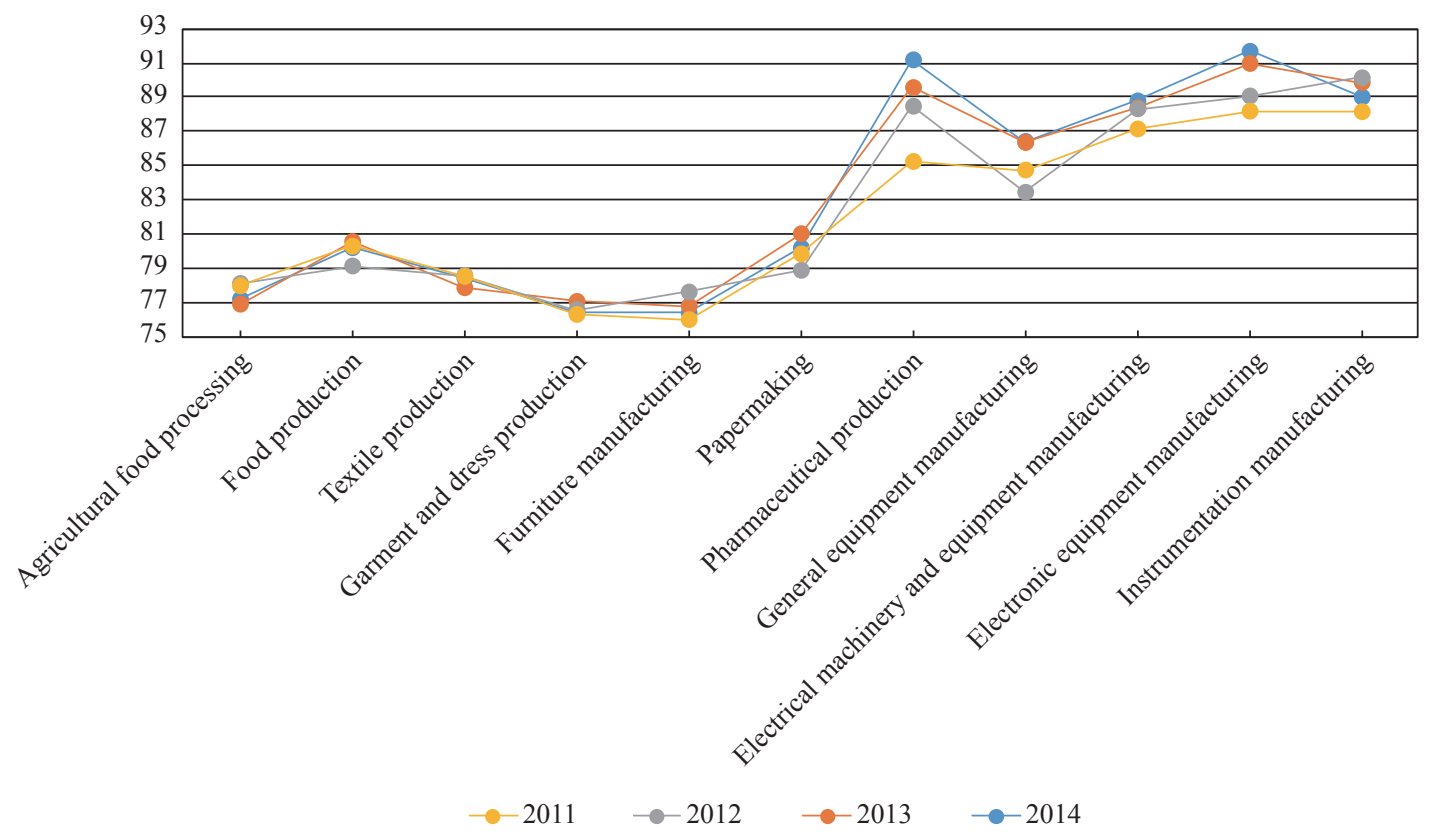

Fig. 2. Quality competitiveness index of aspects of the manufacturing industry in China, 2011-2014.

2025 report; however, such planning may lead to new sources of overcapacity. The Made in China 2025 report also highlights the strategic goal to make China a manufacturing power through a three-step strategy. In this regard, the report emphasizes the 10 developmental fields; namely, new-generation IT, high-end computer numerical control (CNC) machine tools and robots, aerospace equipment, marine engineering equipment and hightech ships, advanced rail transit equipment, energy-saving and new-energy vehicles, power equipment, agricultural machinery, new materials, and biological medicine and high-performance medical instruments. In order to avoid repetition of efforts to develop low-end sectors, the Ministry of Industry and Information Technology has asked a research group to introduce a technical roadmap to guide the development of the 10 fields. In answer to central government's call, local governments have also proposed their plans to develop the manufacturing industry and have chosen key developmental fields. According to relevant surveys, among the 34 provinces, autonomous regions, municipalities, and special administrative regions in China, 30 have introduced local action plans for the Made in China 2025 strategy except Tibet, Taiwan, Hong Kong, and Macao. Further, Heilongjiang Province, Liaoning Province, Inner Mongolia Autonomous Region, and Ningxia Hui Autonomous Region have not yet released a complete version of their action plans. However, when making their action plans, some local governments did not consider development stages and development advantages; Instead, they simply chose 10 key fields in the Made in China 2025 report as the focus of development. Because of limited human and material resources, such an approach will inevitably add to the difficulty attached to the development of advantageous and disadvantageous fields at the same time [6]. As a result, such lo- cal governments will not only fail to achieve their development goals; they will also create new sources of overcapacity on a national scale.

It must be pointed out that there is a high degree of similarity in the key developmental fields of the provinces, autonomous regions, municipalities, and special administrative regions; thus, regional advantages cannot be utilized. Taking energy conservation as an example (see Table 3), 12 regions have decided to give high priority to the development of new-energy vehicles, while 14 regions have focused on the development of power batteries. Among the regions aiming to develop energy-saving and new-energy vehicles, 10 provinces or cities, namely Anhui, Guangxi, Hainan, Hunan, Jiangxi, Shandong, Shaanxi, Sichuan, Zhejiang, and Chongqing, have proposed the development of battery-driven electric vehicles. In addition, six provinces or cities, including Guangxi, Hainan, Hunan, Sichuan and Chongqing, have proposed to develop plug-in hybrid electric vehicles.

\section{Proposals to facilitate the development of China as a manufacturing power}

At present, the two driving forces supporting the fast development of China's manufacturing industry, namely exports and resource cost advantage, have been weakening. As economic growth slows, the Chinese economy has begun to enter a New Normal. In other words, China's manufacturing industry should change from being driven by cost and investment to being driven by innovation. As a large manufacturing country, China is foremost in the world in terms of manufacturing scale; however, the country faces problems such as overcapacity, low quality, and a lack of proprietary intellectual property rights. In order to 
Table 3. The important development directions contained in the local action plans for the China Manufacturing 2025 strategy.

\begin{tabular}{|c|c|c|}
\hline Important development directions & Number of provinces & Names of provinces \\
\hline Robotics & 19 & $\begin{array}{l}\text { Anhui, Beijing, Fujian, Guangxi, Hainan, Henan, Hubei, Hunan, Jilin, Jiangsu, Jiangxi, } \\
\text { Shandong, Shanxi, Shanghai, Sichuan, Tianjin, Yunnan, Zhejiang, Chongqing }\end{array}$ \\
\hline Machine Tools & 17 & $\begin{array}{l}\text { Anhui, Beijing, Fujian, Guangxi, Henan, Hubei, Hunan, Jiangsu, Qinghai, Shandong, } \\
\text { Shanxi, Shanghai, Sichuan, Tianjin, Yunnan, Zhejiang, Chongqing }\end{array}$ \\
\hline New Materials & 17 & $\begin{array}{l}\text { Anhui, Fujian, Gansu, Guangxi, Guizhou, Hubei, Hunan, Jilin, Jiangsu, Qinghai, } \\
\text { Shandong, Shanxi, Shanxi, Sichuan, Tianjin, Yunnan, Zhejiang }\end{array}$ \\
\hline Modern Chinese Medicine & 15 & $\begin{array}{l}\text { Anhui, Gansu, Guizhou, Hebei, Henan, Hunan, Jilin, Jiangsu, Jiangxi, Shandong, Shanxi, } \\
\text { Sichuan, Tianjin, Xinjiang, Zhejiang }\end{array}$ \\
\hline Power Batteries & 14 & $\begin{array}{l}\text { Anhui, Fujian, Hainan, Henan, Hunan, Jiangsu, Jiangxi, Qinghai, Shandong, Shanxi, } \\
\text { Sichuan, Tianjin, Yunnan, Zhejiang }\end{array}$ \\
\hline Sensors & 13 & $\begin{array}{l}\text { Anhui, Beijing, Fujian, Guangxi, Hainan, Hunan, Shandong, Shanghai, Sichuan, Tianjin, } \\
\text { Xinjiang, Zhejiang, Chongqing }\end{array}$ \\
\hline New-energy Vehicles & 12 & $\begin{array}{l}\text { Beijing, Guizhou, Hainan, Heilongjiang, Hubei, Jilin, Shandong, Shanxi, Shanghai, } \\
\text { Tianjin, Xinjiang, Chongqing }\end{array}$ \\
\hline
\end{tabular}

embrace the challenges of the New Normal, China should start with the supply side. In this regard, it should extend reforms in the system and stimulate entrepreneurial innovation. Besides drawing strength from technological innovation, China should also replace the traditional manufacturing style with new-generation IT networks. The manufacturing industry should also play an important role in improving the quality of the national economy. Using the theme of implementing the Made in China 2025 strategy, with its main task of extending the structural reform of the supply side and its goal of improving quality and efficiency, this study offers four suggestions on ways to develop China into a manufacturing power more effectively.

Great efforts should be made to implement high-quality manufacturing projects and transform the style of manufacturing development. Based on the guideline of prioritizing quality, measures should be taken to solve common but difficult problems that are related to the quality of manufactured goods and cannot be solved by the market alone. More public policies and measures in this regard should be adopted and implemented. High-quality manufacturing projects should also be implemented. Starting with key equipment issues and popular consumption related to public welfare, the relevant parties should act to improve the quality of the 10 developmental fields; solve the common problems affecting products' quality, stability, safety, and applicability; and resolve basic technical problems such as standards, measurements, examinations, and certifications. Such high-quality manufacturing projects will provide a solid foundation for realizing the goal of turning China into a manufacturing power by 2025 .

Based on the features of the five key projects, further efforts should be made to facilitate strengthened industrial development at the grassroots level, improve green manufacturing, and ensure the establishment of innovation centers. The successful implementation of intelligent manufacturing should rely on the accurate identification of driving forces. Moreover, governments and enterprises should cooperate with each other closely in order to introduce more digital factories. Based on the stable development of intelligent manufacturing, further efforts should be made to find breakthroughs with regard to green manufacturing, strengthened industrial development at the grassroots level, and innovative systems. This approach will not only ensure the balanced development of manufacturing power; it will also enable the realization of the sustainable, stable, and sound development of China's manufacturing industry.

Further, a new round of key technological projects should be undertaken to facilitate the transformation and upgrade of traditional manufacturing. The requirement of the Central Economic Working Conference of 2016 to revitalize the real economy and apply new technologies and equipment to transform and upgrade traditional manufacturing should be satisfied. It is suggested here that the Central Financial Department should establish a special fund to support a new round of key technological transformation projects. In this regard, the Provincial and Municipal Guide for Made in China 2025 should be adjusted to facilitate coordinated regional development. Further, differentiated policy support should be given based on regional advantages and the actual needs of manufacturing fields and enterprises of different scales in order to stimulate the vitality of regional development. In addition, competitiveness benchmarking of the key developmental fields in different regions should be undertaken. Finally, the primary, secondary, and tertiary manufacturing industry segments should be determined and priority given to each of them to ensure their development.

\section{References}

[1] National Manufacturing Strategy Advisory Committee. Blue book on Made in China 2025 (2016) [M]. Beijing: Publishing House of Electronics Industry, 2016. Chinese.

[2] The CAE Center for Strategic Studies, Chinese Academy of Machinery Science \& Technology. China manufacturing power development report (2015) [R]. Beijing: Chinses Academy of En- 
gineering, 2016. Chinese.

[3] Chen H X, Wu Y H. Wuhan costs 160 million RMB to conduct the largest memory base in China [N]. 21st Century Business Herald, 2016-03-29(3). Chinese.

[4] $\mathrm{Xu} \mathrm{S} \mathrm{T.} \mathrm{To} \mathrm{make} \mathrm{manufacturing} \mathrm{innovation} \mathrm{center} \mathrm{successful} \mathrm{[J]}$ Fortune World, 2016 (4): 46-48. Chinese.
[5] She H M. The exploration and practice of innovation by Xi'an institute of optics and precision mechanics of CAS [N]. Economic Daily, 2016-09-05(13). Chinese.

[6] Li B Z, Xu H L. Study on the differences of innovation policy in regional innovation system $[\mathrm{J}]$. Science of Science and Management of S. \&T., 2007, 28(3): 50-54. Chinese. 